\title{
Modern methods of corono-radicular restoration of a lateral tooth with an endodontic treatment
}

\author{
Metode moderne de restaurare corono-radiculară a unui \\ dinte din zona posterioară tratat endodontic
}

\author{
Anca-Elena But, Paula Perlea, Alexandru Titus Farcaşiu, Mihaela-Rodica Păuna \\ Facultatea de Medicină Dentară, Universitatea de Medicină şi Farmacie „Carol Davila“, \\ Bucureşti, România
}

\begin{abstract}
Most of the teeth that require endodontic treatment have been affected by extensive caries. These weakened them, increasing their risk of fracture and making their restoration much more difficult for the dento-maxillary function to restore. Modern dentistry offers various possibilities for restoring endodontically treated teeth. The best option is selected by the clinician according to the clinical case particularities. This article is a summary of the modern methods used for restoring a lateral tooth with an endodontic treatment.

Keywords: endodontic treatment, restoration

REZUMAT

Majoritatea dinţilor care necesită tratament endodontic au fost afectaţi în prealabil de procese carioase masive. Acestea le-au subminat rezistenţa, crescându-le riscul de fractură şi îngreunându-le restaurarea pentru reluarea funcţiilor în cadrul aparatului dento-maxilar. Stomatologia modernă oferă numeroase posibilităti de restaurare a dinţior cu tratament endodontic, dând posibilitatea medicului stomatolog să aleagă metoda ideală în funcţie de fiecare caz clinic în parte.

Acest articol îşi propune o trecere în revistă a metodelor actuale de restaurare a unui dinte lateral care a suferit tratament endodontic.
\end{abstract}

Tratamentele endodontice reprezintă baza de suport pentru restaurările protetice realizate în scopul de a relua funcțiile principale ale aparatului dentomaxilar. Tratamentul endodontic se consideră un succes atunci când dintele este asimptomatic, pe radiografie lipsesc reacțiile apicale şi se reiau funcțiile masticatorie şi estetică. De cele mai multe ori, dinții laterali care necesită tratament endodontic prezintă pierdere mare de substanță dentară, ceea ce face ca decizia de tratament să fie una complexă. Aceasta implică o colaborare strânsă între medicul endodont şi cel protetician, deoarece tratamentul unui dinte trebuie considerat finalizat doar atunci când acesta este restaurat coronar pentru a-şi relua funcția masticatorie.
Riscul de fractură este mai mare la dinții devitali comparativ cu cei vitali din cauza modificărilor structurale pe care aceştia le suferă ca urmare a pierderii vitalităţii. Factori cum ar fi rasa, sexul, vârsta, tipul de dinte şi cantitatea de substanță dentară pierdută prin carie influențează acest aspect (1).

De aceea, aceşti dinţi necesită consideraţii speciale în decizia de restaurare, mai ales atunci când pierderea de substanță dentară este masivă, fiind nevoie atât de retenţie maximă, cât şi de creşterea rezistenței la fractură (2).

Studiile au arătat că momentul restaurării coronare este important. $\mathrm{Cu}$ cât restaurarea coronară este realizată mai repede după finalizarea tratamen- 
tului endodontic, cu atât scade riscul de fractură coronară sau corono-radiculară şi riscul de microinfiltrație marginală, iar prognosticul tratamentului devine mai favorabil.

De-a lungul timpului, s-au folosit numeroase metode de restaurare a dinților cu tratament endodontic şi s-au publicat sute de articole dedicate acestui aspect al stomatologiei. Deşi cunostințele despre complicațiile care pot apărea la dinții devitali s-au îmbunătățit, acest subiect rămâne complex şi controversat (3). Indiferent de metoda de restaurare aleasă, obiectivele tratamentului rămân neschimbate: să nu existe simptomatologie clinică, să se obțină o sigilare bună, atât endocanalară, cât şi coronară, dintele să îşi recapete funcția masticatorie şi să aibă o estetică satisfăcătoare.

În restaurarea unui dinte cu tratament endodontic, primul pas important este realizarea unui plan de tratament corect. De aceea, medicul endodont are un rol esențial în succesul recuperării dintelui respectiv. El trebuie să decidă dacă dintele merită sau nu tratat sau retratat, nu doar din punct de vedere endodontic, ci şi din punct de vedere protetic. În acest sens, se ține cont de mai multe aspecte. Unele influențează decizia de tratament din punct de vedere endodontic: dimensiunea leziunii apicale, afectarea sau nu a furcației radiculare sau a spațiului periodontal, raportarea la formațiunile anatomice învecinate. Alte aspecte trebuie avute în vedere pentru a se putea realiza o restaurare protetică corectă: cantitatea şi calitatea substanței dentare rămase în urma îndepărtării procesului carios, respectarea înălțimii biologice şi raportul coroanărădăcină. Dacă rezultatul acestei evaluări este unul satisfăcător, toți aceşti factori vor permite dintelui să fie inclus într-un plan de tratament corect.

Dinții devitali suferă anumite modificări structurale cum ar fi pierderea apei şi desfacerea legăturilor de colagen de la nivelul dentinei (1). Ei devin mai casanți şi li se modifică capacitatea de adeziune. De asemenea, prepararea cavității de acces reduce rezistenţa cuspidiană şi creşte riscul de fractură.

Tipul de restaurare coronară se alege în funcție de cantitatea de substanță dentară rămasă. În vederea realizării unei restaurări directe şi imediate, se pot utiliza materiale provizorii sau definitive. S-a demonstrat, totuşi, că realizarea unei obturaţii provizorii creşte riscul apariției microinfiltrației mar- ginale şi, implicit, a cariei secundare, de aceea, se preferă realizarea cât mai rapidă a unei restaurări coronare definitive.

Unul dintre materialele cu utilizare largă în trecut a fost amalgamul de argint. Acesta nu oferea un aspect estetic, nu era conservativ cu substanța dentară deoarece necesita o anumită formă a cavităţii pentru a-i putea asigura retenția, iar cariile secundare apărute ca urmare a lipsei de adeziune la interfața dinte-obturație determinau reinfectarea sistemului endocanalar şi creşteau riscul de fractură coronară. În prezent, amalgamul de argint are utilizare restrânsă.

Îmbunătăţirea adeziunii şi a materialelor compozite, cu proprietăți asemănătoare cu cele ale structurilor dentare, permit medicului stomatolog opțiunea de a realiza o restaurare conservativă şi imediată, capabilă să sigileze şi să protejeze dintele în vederea amânării realizării unei coroane de acoperire, cu sacrificiu ulterior de substanță dentară (4).

Deşi restaurările compozite oferă o rezistență la fractură mai bună decât amalgamul de argint, având adeziune la structurile dentare subiacente, contracția de fotopolimerizare rămâne o problemă. Aceasta determină stres la interfaţa dintre dinte şi restaurare, iar când stresul depăşeşte forța de adeziune, apare desprinderea obturației cu apariția microinfiltrației marginale. Studiile au arătat că folosirea stratificării în tehnica de obturație cu materiale compozite reduce stresul apărut ca urmare a contracției de fotopolimerizare, spre deosebire de materialele folosite în calup, la nivelul cărora nu se poate controla coeficientul de contracție. La fel şi realizarea unui strat hibrid între restaurare şi dinte, prin folosirea unei răşini adezive sau a unui liner cu vâscozitate scăzută, capabile să absoarbă o parte din forțele apărute la această interfață (5).

Dacă pentru cavităţile de acces mici restaurările adezive directe cu materiale compozite se consideră a fi o soluție eficientă pe termen scurt şi mediu, pentru cavităţile mezio-ocluzo-distale se preferă realizarea unor restaurări indirecte de tip inlay, onlay sau overlay, care pot oferi o protecție cuspidiană eficientă, crescând rezistența dintelui la fracturi (4).

Restaurările de tip inlay nu refac cuspizii dentari, de aceea nu oferă protecție cuspidiană în mişcările funcționale. Onlay-urile şi overlay-urile în 
schimb, înlocuiesc cuspizii lipsă şi realizează protecția cuspidiană. În acest caz, stopurile ocluzale se realizează la nivelul restaurării protetice (6).

Aceste piese protetice sunt realizate în laborator şi sunt cel mai frecvent din materiale ceramice sau compozite. În prezent se utilizează tehnologia CAD/CAM. Ele se cimentează adeziv pe dinte sub izolare cu diga, reducând astfel riscul de microinfiltrație. Sunt indicate în locul obturațiilor clasice datorită proprietăților mecanice superioare şi a eliminării riscului de contracție după priză. Spre deosebire de coroanele de acoperire, ele conservă mai mult din structura dură dentară.

Majoritatea dinților ce necesită tratament endodontic prezintă carii extinse în suprafață. Când se pierde foarte mult din structura coroanei dentare, restaurarea dinților devitali este frecvent asociată cu folosirea pivoților dentari. În trecut, se credea că aceştia cresc rezistența dinţilor, dar s-a demonstrat că ei se folosesc numai pentru a putea susține restaurarea coronară şi a realiza legătura dintre aceasta şi rădăcina dentară. De asemenea, dacă spațiul pentru aplicarea pivotului nu este realizat corect, în timpul preparării pot apărea diverse accidente care pot compromite tratamentul endodontic. Deşi rare, printre acestea se numără realizarea unor perforații sau fractura rădăcinii (3). Acest lucru contribuie la diferențierea deciziei de a folosi pivoți între dinţii anteriori şi cei posteriori.

Indiferent de tipul de pivot folosit, acesta trebuie să prezinte o serie de caracteristici pentru a îşi îndeplini scopul principal, acela de a susține restaurarea coronară a bontului subiacent unei coroane de acoperire: să fie conservator cu rădăcina dentară restantă, să aibă modulul de elasticitate apropiat de cel al dentinei pentru a putea prelua şi transmite forțele laterale în axul lung al dintelui, să fie rezistent şi să ofere retenție materialului de restaurare coronară.

Există mai multe tipuri de pivoți. Pivoții metalici pot fi turnați, prefabricați sau înşurubați (Fig. 1, Fig. 2).

Aceştia au utilizare din ce în ce mai restrânsă deoarece necesită subțierea excesivă a pereților radiculari, fiind neconservatori cu substanța dentară (Fig. 3). De asemenea, materialul de cimentare folosit nu are adeziune chimică şi apar frecvent carii secundare ca urmare a microinfiltrației marginale.

Pivoții din zirconiu sunt albi, radioopaci şi foarte rigizi. Au un modul de elasticitate mai mare de-

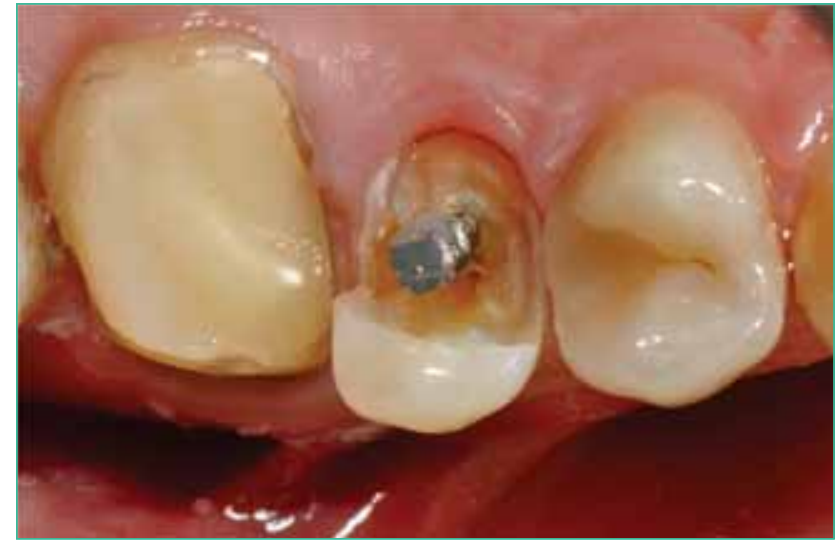

FIGURA 1. Pivot metalic înşurubat la nivelul rădăcinii palatinale a lui 1.5. Dintele a avut o obturație de compozit care s-a fracturat

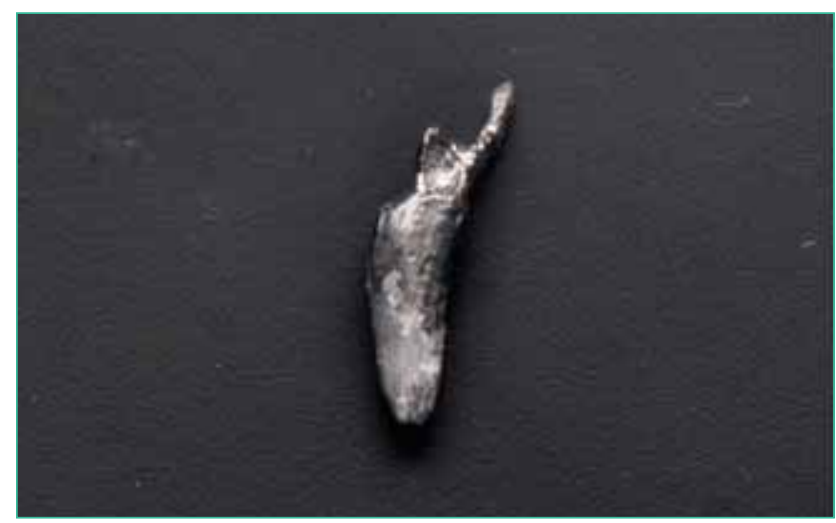

FIGURA 2. Pivot metalic turnat

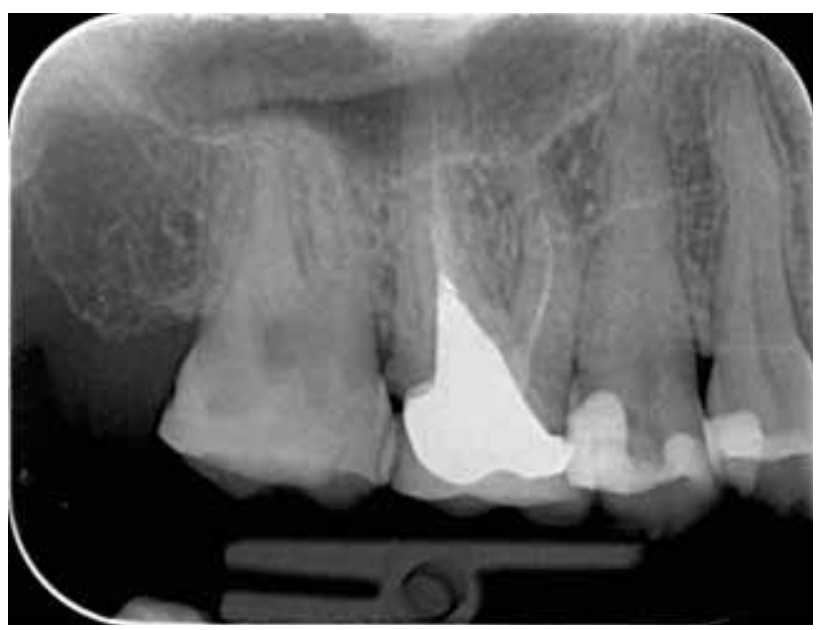

FIGURA 3. 1.6 restaurat cu pivot metalic turnat şi coroană din acrilat. Rădăcina palatinală prezintă fisură oblică spre furcație din cauza transmiterii incorecte a forțelor prin intermediul restaurării şi a subțierii excesive a pereților radiculari.

cât cel al oțelului inoxidabil, ceea ce determină apariţia unui stres mai mare la intrarea în canal şi un risc de fractură mai mare decât în cazul pivoților metalici sau al celor din fibră de carbon (2).

Cea mai largă utilizare în prezent o au pivoții prefabricați din fibră de sticlă (Fig. 4). Comparativ 
cu cei metalici, ei sunt mai puțin rigizi şi, drept urmare, distribuie mai uniform forțele la nivelul rădăcinii, ceea ce duce la reducerea fracturilor radiculare după realizarea restaurării (7). De asemenea, ei au o culoare translucentă şi îmbunătățesc estetica restaurării finale şi permit trecerea luminii pentru fotopolimerizarea materialului de cimentare. Aceştia se găsesc în diferite forme. Pot fi cilindrici, conici sau cilindo-conici. S-a demonstrat că cei cilindrici distribuie uniform forțele care survin asupra rădăcinii dentare, dar cei cilindro-conici sunt mai conservatori cu dentina radiculară, imitând forma naturală a rădăcinii şi transmițând forțele cât mai uniform pe suprafața acesteia (3).

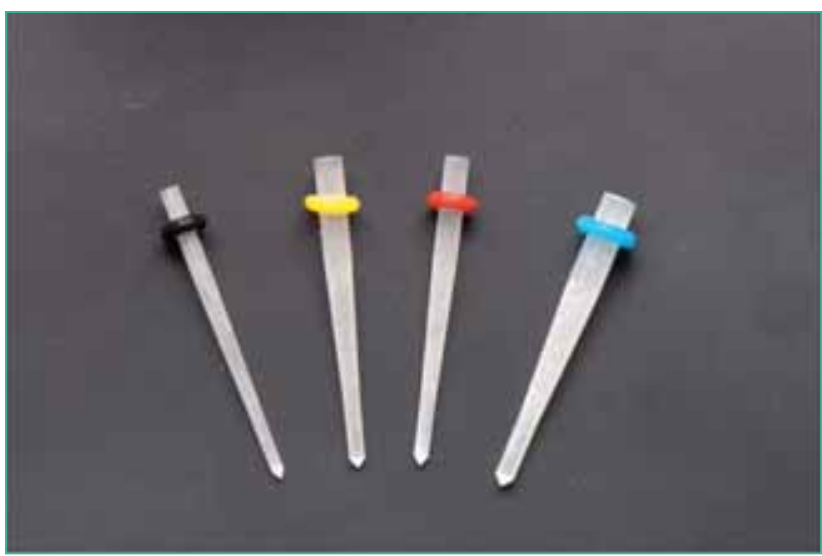

FIGURA 4. Pivoți cilindro-conici din fibră de sticlă.

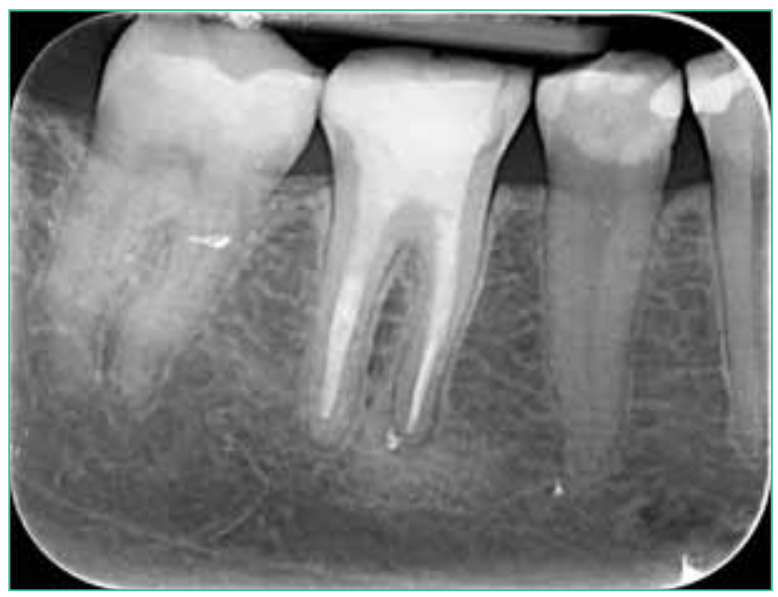

FIGURA 5. 4.6 restaurat cu 2 pivoți din fibră de sticlă, unul inserat pe rădăcina distală şi altul pe rădăcina meziolinguală. Pentru refacerea coronară s-a folosit compozit fluid fotopolimerizabil şi compozit nanohibrid cu polimerizare duală.

Pentru restaurare se folosesc un număr de pivoți proporțional $\mathrm{cu}$ gradul distrucției coronare care se cimentează adeziv în interiorul rădăcinii, folosind materiale compozite pentru înlocuirea tesuturilor dentare pierdute (Fig. 5). Aceasta trebuie conside- rată o structură provizorie, peste care urmează să se realizeze o coroană de acoperire pentru a se putea sigila accesul la canalele radiculare şi pentru a preveni reinfiltrarea acestora (Fig. 6).

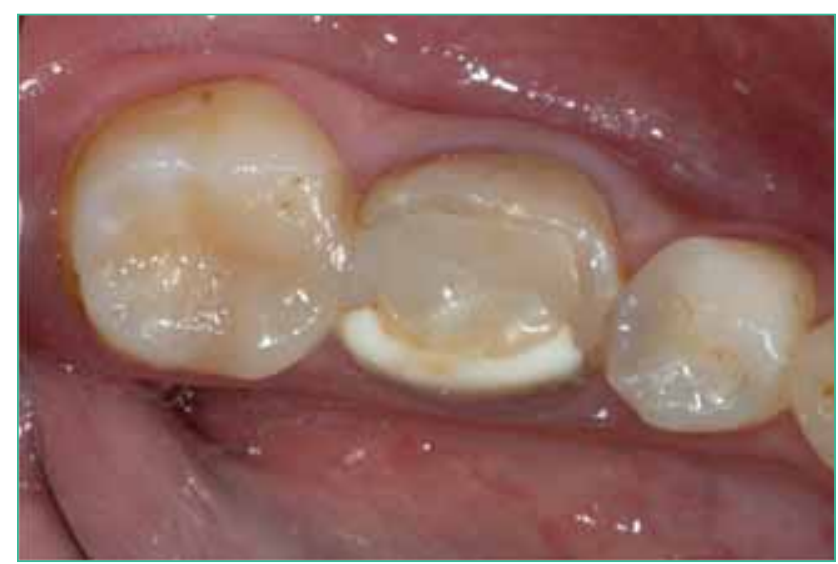

FIGURA 6. 4.6 restaurat cu pivoți din fibră de sticlă şi material compozit nu a primit coroană de acoperire timp de 3 ani. Se observă apariția cariei secundare ca urmare a microinfiltrației marginale.

Numeroase studii realizate în ultimii ani au demonstrat că, deşi pentru dinții anteriori realizarea unei coroane de acoperire nu a îmbunătăţit semnificativ rata de succes, pentru dinții laterali există o rată de succes de până la 6 ori mai mare dacă aceştia au fost restaurați protetic cu coroană de acoperire (8).

Realizarea coroanelor de acoperire pe dinții cu tratament endodontic este considerată în prezent ca fiind standardul de aur care poate asigura succesul pe termen lung al tratamentului respectiv şi reintegrarea dintelui în funcțiile aparului dento-maxilar (7).

Planul de tratament trebuie gândit pornind de la întrebarea: Este acest dinte restaurabil din punct de vedere protetic? Daca da, se trece la efectuarea tratamentului endodontic. Unul dintre criteriile de care trebuie să se țină cont în decizia de a tratata sau nu un dinte se referă la structura dentară restantă. Sunt necesari 4-5 mm de structură dentară deasupra osului alveolar pentru a proteja atât înălțimea biologică, cât şi pentru a asigura efectul de ferulă. Efectul de ferulă se creează între pereții dentari şi marginile coroanei. Sunt necesari minimum 1,5 mm, ideal 2-3 mm de structură dentară sănătoasă apical de marginea preparației, pentru a permite coroanei de acoperire să încercuiască preparația.

Prezența ferulei reduce semnificativ riscul de fractură prin consolidarea dintelui şi disiparea for- 
țelor care se concentrează în porțiunea cea mai îngustă a dintelui. De asemenea, determină absorbția corespunzătoare a forțelor laterale provenite de la nivelul pivoților şi reduce efectul de pârghie, crescând rezistența şi retenția restaurării. $O$ ferulă mai lungă creşte rezistența dintelui în mod semnificativ (9).

Dintre opțiunile disponibile, coroanele metalice, metalo-acrilice şi metalo-compozite şi-au pierdut din utilizare în ultimul deceniu, luându-le locul cele metalo-ceramice, cele cu substructură internă din zirconiu sau ceramică şi cele monolitice din ceramică vitroasă sau zirconiu.

Tipul de coroană se alege în funcție de situația clinică. Dacă este posibil, se preferă utilizarea unei coroane monolitice, deoarece prezintă avantajul major al economiei de substanță dură dentară, lucru important mai ales pentru dinții cu tratament endodontic, care au suferit deja în urma afectării de către procesul carios (Fig. 7, Fig. 8).

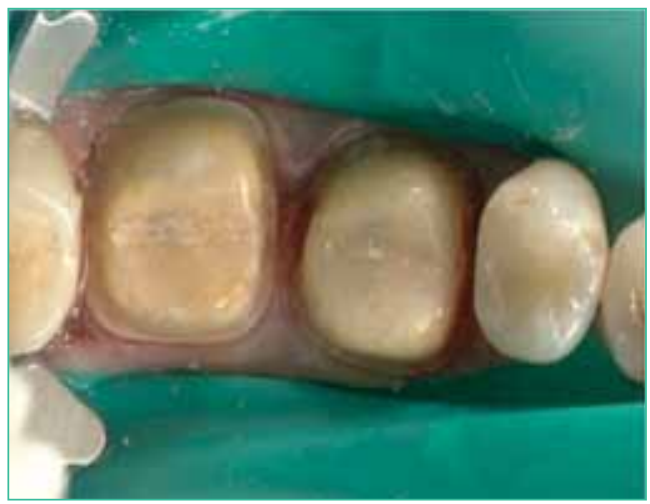

FIGURA 7. 4.6 şi 4.7 restaurați cu pivoți din fibră de sticlă şi material compozit nanohibrid cu polimerizare duală, preparati pentru coroane E-max monolitice. Izolare cu diga pentru cimentare adezivă

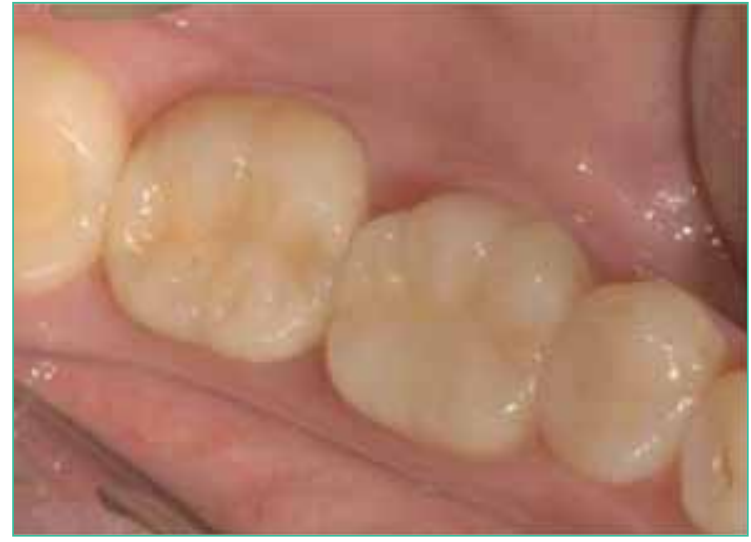

FIGURA 8. 4.6 şi 4.7 restaurați cu pivoți din fibră de sticlă şi compozit cu polimerizare duală, restaurați cu coroane de acoperire E-max monolitice.

Coroanele din zirconiu integral nu pot atinge aceleaşi cerințe estetice precum cele din ceramică, dar sunt preferate la pacienții cu parafuncții datorită rezistenței crescute a acestui material (6).

Metodele de restaurare a dinților trataţi endodontic au determinat de-a lungul timpului numeroase controverse şi reprezintă subiectul multor studii de specialitate. Deşi restaurarea finală este realizată de către medicul protetician, decizia de a trata sau nu un dinte revine medicului endodont, care trebuie să ţină cont de toate criteriile importante pentru a putea reintegra în funcție dintele respectiv. Cerințele stomatologiei actuale sunt din ce în ce mai exigente şi, de aceea, metodele de restaurare care oferă adeziune şi estetică maximă au devenit prioritare chiar şi pentru dinții laterali.

Mulțumiri domnului doctor Alecsandru Ionescu pentru sprijinul şi colaborarea în realizarea cazuisticii pentru acest articol.

Conflict of interest: none declared Financial support: none declared

\section{BIBLIOGRAFIE}

1. Lapria Faria A., Silveira Rodrigues R., Pereira de Almeida Antunes R. et al. Endodontically treated teeth: Characteristics and considerations to restore them. Rez. in: Journal of Prosthodontic Research. 2011; 55: 69-74

2. McComb D. Restoration of the Endodontically Treated Tooth, DISPATCH, 2008; Supplement February/March: 2-18.

3. Schwartz R., Robins J. Post Placement and Restoration of Endodontically Treated Teeth: A Literature Review. JEndod. 2004; 30: 289-301.

4. Polesel A. Restoration of the endodontically treated posterior tooth. Giornale Italiano di Endodonzia. 2014; 28: 2-16.

5. Belli S., Eraslan O., Eskitascioglu G. Direct Restoration of Endodontically Treated Teeth: a Brief Summary of Materials and Techniques. Dental Restorative Materials. 2015; 2: 182-189.

6. Lăzărescu F. Incursiune în estetica dentară, Bucureşti: SSER, 2013: 268-283.

7. Machado J., Almeida P., Fernandes S. et al. Currently used systems of dental posts for endodontic treatment. Procedia Structural Integrity. 2017; 5: 27-33.

8. Prakash Tikku A., Chandra A., Bharti R. Are full cast mandatory after endodontic treatment in posterior teeth? J Conserv Dent. 2010; 13: 246-248.

9. Hargreaves K.M., Berman L.H., Rotstein I. Cohen's Pathways of the Pulp Eleventh Edition, Missouri, Elsevier, 2015. 